\title{
EDITORIAL
}

\section{RESISTÊNCIA COMO CIRCULAÇÃO E FOMENTO DO PENSAMENTO CRÍTICO}

O primeiro número da Revista Comunicações de 2021 está disponível para leitura e, em meio a tantos reveses pelos quais passamos na contemporaneidade: ainda sofrendo as consequências da Pandemia Mundial da Covid-19, que parece não arrefecer no Brasil, com a Educação Básica e o Ensino Superior perecendo com a falta de investimentos públicos que afetam ainda a produção de ciências e a sustentabilidade desse fazer, consideramos essa publicação um ato de resistência. Resistência como circulação e fomento do pensamento crítico. Estar vivo, promover o compartilhamento do conhecimento e a promoção de saberes em nosso país é resistir. Assim, a presente publicação, mais uma vez, cumpre o intento da Revista Comunicações de promover a divulgação da pesquisa acadêmica e fomentar o debate sobre questões atuais e significativas para a compreensão dos fenômenos educativos. Esta publicação é composta por dezesseis manuscritos: quatorze artigos e dois ensaios.

E, por falar em processos de (re)existir, os primeiros manuscritos trazidos neste volume, abordam temas inclusivos. O artigo POLÍTICAS DE TECNOLOGIAS EDUCACIONAIS: INTERDISCIPLINARIDADES E PRÁTICAS DE INCLUSÃO DIGITAL, de Roberta Mirnas de Oliveira Gomes e Jean Mac Cole Tavares Santos, propõe analisar as políticas de tecnologias educacionais, o Programa Nacional de Tecnologia Educacional - PROINFO e o Programa um Computador por Aluno - PROUCA, em uma perspectiva interdisciplinar. Em seguida, no artigo PRÁTICAS PEDAGÓGICAS NA EDUCAÇÃO INCLUSIVA: REVISÃO SISTEMÁTICA, Lêda Gonçalves de Freitas, Carla Cristie de França Silva, Cláudia Cristina Fukuda e Gustavo Francisco Neto, analisam a inclusão escolar, a partir das práticas pedagógicas, como pressuposto essencial para a democratização da escola. No texto $I D O$ SOS NA EDUCAÇÃO DE JOVENS E ADULTOS NO MUNICÍPIO DE JOÃO PESSOA: UMA REALIDADE VISÍVEL, de Saulo José Veloso de Andrade, Theóffillo Silva Lopes e Eduardo Jorge Lopes da Silva, são analisados os dados quantitativos que registram a presença de educandos idosos nas escolas municipais de João Pessoa-PB, sinalizando para o estreitamento entre o atendimento de idosos no contexto educacional e o crescimento desse público no contexto da sociedade. Em SONHO DE LIBERDADE: A CRIAÇÃO DE UM VIDEOCLIPE NO CASE-SM, os autores João Pedro Wizniewsky Amaral, Rafael Salles Gonçalves e Thomás Dalco Townsend discutem os impactos positivos da criação em audiovisual na socioeducação, que melhoram o desenvolvimento individual e social de jovens em conflito com a lei. 
As questões de gênero também são contempladas nesta publicação. O artigo $G \hat{E}$ NERO E EDUCAÇÃO DE JOVENS E ADULTOS: NOVO OLHAR PARA A EDUCAÇÃO FÍSICA ESCOLAR, de Lucas Baptista Mousinho Lins e Rosa Malena de Araújo Carvalho, problematiza o tema gênero presente em algumas orientações curriculares municipais do Estado do Rio de Janeiro direcionadas à Educação de Jovens e Adultos (EJA). Em REPRESENTAÇÕES DE GRADUANDAS DE EDUCAÇÃO FÍSICA SOBRE CORPO, MULHER E MÍDIA, Dieli Martins Queiroz e Vagner Matias do Prado problematizam as percepções de estudantes sobre a relação entre corpo, mulher e mídia, na perspectiva culturalista e dos estudos de gênero.

O currículo, a vivência escolar e as políticas educacionais e de formação são trazidos à lume nos artigos, como no texto PERFIL E TRAJETÓRIAS DE ESTUDANTES EM CURSOS DE PÓS-GRADUAÇÃO STRICTO SENSU NO MERCOSUL: "É PRESENCIAL, $N E ́$ ?", de Priscilla Campos de Castro e Carlos Lopes, que identifica e analisa o perfil de oito brasileiros que cursaram a pós-graduação stricto sensu em dois países do Mercosul - Paraguai e Argentina -, suas percepções sobre a modalidade do curso e a questão do reconhecimento do diploma. Em REPRESENTAÇÕES SOCIAIS E MAPAS AFETIVOS: VIVENNCIAS JUVENIS NA ESCOLA PÚBLICA, de Francisca Denise Silva Vasconcelos, Luana Paiva da Silva, Jorge Samuel de Sousa Teixeira, Bárbara Ellen Viana Sales, Gracymara Mesquita Severiano e Juliana Maria do Nascimento Mota, são discutidas as Representações Sociais produzidas pelos estudantes a partir do seu ambiente escolar. No artigo A BASE NACIONAL COMUM CURRICULAR (BNCC): ONDE ESTÁ O LAZER?, Carlos Alberto Fonseca, Cáthia Alves e Hélder Ferreira Isayama nos trazem a descrição e análise do tratamento dado ao tema do lazer na Base Nacional Comum Curricular (BNCC), no contexto da educação infantil e do ensino fundamental. OUTRAS HEGEMONIAS EM PESQUISAS SOBRE CURRÍCULOS TRANSNACIONAIS, de Maria da Graça Moreira da Silva; Fernando José de Almeida; Lucila Rupp, destaca concepções curriculares contra-hegemônicas aos modelos imperantes e aponta possíveis epistemologias que se contrapõem às matrizes do neoliberalismo. O artigo PERCEPÇÕES DOS PROFESSORES DE UMA ESCOLA DA REDE PÚBLICA DO DISTRITO FEDERAL SOBRE A AVALIAÇÃO NACIONAL DA ALFABETIZAÇÃO (ANA), de Thamara Maria de Souza e Robson Dias, analisa como a Avaliação Nacional da Alfabetização (ANA) é percebida pelos professores do Bloco Inicial de Alfabetização (BIA) de uma escola classe da rede pública de ensino do Distrito Federal (DF). No artigo FORMAÇÃO CONTINUADA DE PROFESSORES: UM ESTUDO EXPLORATÓRIO NO RIO GRANDE DO SUL, Marcelo Fonseca Vivian Mara e Elisângela Jappe Goi apresentam os dados de uma pesquisa realizada em quatro Coordenadorias Regionais de Educação (CRE) do Estado do Rio Grande do Sul e observam os aspectos referentes a características gerais de ações de formação continuada, assuntos abordados e a formação específica para professores de cada área do conhecimento.

O presente voluma ainda conta com o artigo HISTÓRIAS EM QUADRINHOS E O ENSINO DE QUÍMICA: PERCEPÇÃO DOCENTE DE UMA PROPOSTA INVESTIGATI$V A$, de Leonardo André Testoni, Solange Wagner Locatelli, Simone Alves de Assis Martorano e Marco Antônio dos Santos, que propõem uma sequência didática baseada no uso de HQ e a analisa a partir das percepções do docente que a aplicou, enfatizando a relevância 
das Histórias em Quadrinhos para a educação química. No texto UM ESTUDO SOBRE A REVISTA BRASILEIRA DE HISTÓRIA DA EDUCAÇÃO (2001-2017): AUTORIAS, TEMAS E CITAÇÕES, Marisa Bittar, Olivia Morais de Medeiros Neta e Amarilio Ferreira Junior analisam as publicações da Revista Brasileira de História da Educação (RBHE) e refletem sobre a importância em si do mapeamento dessa produção para a formação de grupos, a troca de informações e o intercâmbio internacional nessa área de conhecimento.

Por fim, esta edição conta com dois ensaios. Em CRIANÇAS, LEITURA, ESCRITA E SIGNIFICAÇÃO: A VIDA COMO ESCOLA E A ESCOLA COMO VIDA!, Raimundo Nonato de Oliveira Falabelo traz reflexões sobre práticas de alfabetização em classes iniciais do ensino fundamental, observando como a aprendizagem pode articular o conhecimento sistematizado, as singularidades, diversidades e heterogeneidades sociais e culturais das crianças. No ensaio REVISÃO DE LITERATURA SOBRE A EXPERIMENTAÇÃO INVESTIGATIVA NO ENSINO DE CIENNCIAS, de Ana Flávia Correa Leão e Mara Elisângela Jappe Goi, encontramos uma revisão de literatura sobre o assunto Experimentação Investigativa no Ensino de Ciências, que se apresenta como potencial estratégia metodológica nos processos de ensino e aprendizagem no Ensino de Ciências e na formação de alunos críticos e investigativos.

Este editorial diz muito pouco da riqueza dos trabalhos reunidos, por isso, convidamos leitoras e leitores para embrenharem-se neste volume da Revista Comunicações, preparado com muito esmero, para a descoberta das contribuições de cada texto e o início de outros diálogos.

Encerramos com o fundamental reconhecimento do trabalho da Profa. Dra. Rita de Cassia Antonia Nespoli Ramos, Presidente da Comissão Editorial desta revista até o mês de abril de 2021, da dedicação de Ana Caroline Franco e Maria Zélia Firmino de Sa, da equipe editorial e de outros profissionais sem os quais essa edição não seria possível. Deixamos nossa profunda gratidão pela companhia nas lutas diárias e, nós, que realizamos o trabalho docente cotidianamente, em uma conjuntura adversa, nos alentamos nas palavras de Freire, em Pedagogia da Autonomia (1996, p. 60):

Gosto de ser gente porque, mesmo sabendo que as condições materiais, econômicas, sociais e políticas, culturais e ideológicas em que nos achamos geram quase sempre barreias de difícil superação para o cumprimento de nossa tarefa histórica de mudar o mundo, sei também que os obstáculos não se eternizam.

Renata Helena Pin Pucci

Editora

\section{REFERÊNCIA}

FREIRE, Paulo. Pedagogia da Autonomia: saberes necessários à prática educativa. São Paulo, Paz e Terra, 1996. 